\title{
Effect of Ti Addition on the Microstructure and Property of FeAICuCrNiMo 0.6 High-Entropy Alloy
}

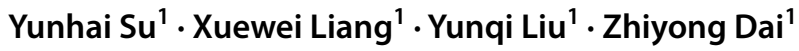

Received: 10 September 2019 / Revised: 1 December 2019 / Published online: 17 March 2020

(c) The Chinese Society for Metals (CSM) and Springer-Verlag GmbH Germany, part of Springer Nature 2020

\begin{abstract}
$\mathrm{FeAlCuCrNiMo}_{0.6} \mathrm{Ti}_{x}(x=0.2,0.6,0.8)$ high-entropy alloys were fabricated with flux-cored wire and surfaced on low-carbon steel by gas metal arc welding. The effect of Ti addition on the microstructures and properties of $\mathrm{Fe} \mathrm{AlCuCrNiMo}_{0.6} \mathrm{Ti}_{x}$ HEAs surfacing layer was systematically studied. The results show that $\mathrm{FeAlCuCrNiMo} \mathrm{C}_{0.6} \mathrm{Ti}_{x} \mathrm{HEAs}$ surfacing layer exhibits a majority of BCC solid solution based on $\mathrm{Fe}-\mathrm{Cr}$ phase and a small amount of $\mathrm{MC}$ phase. Microhardness and wear tests results show that the addition of Ti can significantly improve the microhardness and wear resistance of the surfacing layer. The microhardness of surfacing layer can reach up to $642 \mathrm{HV}_{0.5}$, which is about 2.8 times that of the substrate. Meanwhile, the wear mass loss is minimum. Electrochemical corrosion test results show that the addition of Ti can improve the corrosion resistance of surfacing layer, which is better than 304 stainless steel substrate. With the increase in Ti, the corrosion resistance increases first and then decreases. When the Ti content is 0.6 , the self-corrosion current density of polarization curve is the smallest, the capacitive impedance radius of electrochemical impedance spectroscopy is the largest, and the corrosion resistance effect is the best.
\end{abstract}

Keywords High-entropy alloy $\cdot$ Surfacing $\cdot$ Flux-cored wire $\cdot$ Microstructure $\cdot$ Microhardness $\cdot$ Wear resistance Electrochemical corrosion

\section{Introduction}

In traditional alloys, one or two metal elements are used as the main elements (the content is more than 50\%), and the remaining metal or non-metal elements are used as trace complementary elements to improve the properties of alloys. With the increasing element, intermetallic compounds including brittle phase will precipitate within the alloy, and the properties of the alloy will seriously decline [1]. The concept of the high-entropy alloys was firstly introduced in 1995, in a master's research paper [2]. High-entropy alloy (HEA) refers to a new type of alloy material without major components and with the same or similar atomic percentages of each component, which is characterized by large atomic chaos, multiple components and simple phase [3, 4].

Available online at http://link.springer.com/journal/40195.

Yunhai Su

su_yunhai@sut.edu.cn

1 School of Materials Science and Engineering, Shenyang University of Technology, Shenyang 110870, China
Through reasonable alloy formulation design, alloy materials with high hardness, high strength, high wear resistance, corrosion resistance and other excellent characteristics can be obtained [5-8], which has been widely investigated by researchers. In the study of alloys, the types and contents of elements are adjusted so that they have a unique microstructure and a variety of properties. Zhou et al. [9] prepared $\mathrm{AlCoCrFeNiTi}_{x}$ HEAs with a single body-centered cubic (BCC) structure for the first time and carried out relevant researches on composition optimization. Sun et al. [10] prepared various alloys each of which had 5-8 elements, such as $\mathrm{AlFeCuCoCr}, \mathrm{AlFeCuNiCrV}$, AlFeCuCoNiCrTi and AlFe$\mathrm{CuCoNiCrTiV}$, to study the impact of the element number on the microstructure and performance of HEAs. Results show that the alloy microstructure has a trend of transition from dendrites to equiaxed crystal. The hardness of alloy increases with the element number. Otto et al. [11] prepared CoCrFeMnNi alloy by arc melting and cold rolling and studied the change of mechanical properties with temperature at low temperature range.

Titanium alloy has high strength, low density, strong corrosion resistance, high temperature stability and other excellent 
properties, so the addition of Ti in HEAs can combine the excellent properties of HEA with those of titanium alloy. In addition, $\mathrm{Ti}$ is a passivated film-forming element with good corrosion resistance, so the properties of HEA containing $\mathrm{Ti}$ are widely investigated. The mechanical properties and corrosion resistance of HEAs containing Ti have been studied recently [12-15]. The preparation technology of HEA includes vacuum melting casting, powder metallurgies and surface modification. Block HEAs are mainly prepared with vacuum arc furnace melting and melt casting $[16,17]$, but the size is limited. Therefore, the preparation of large HEA composite materials by depositing HEA on low-carbon steel surface is necessary. It can reduce the cost of raw materials or avoid the replacement of parts, which is of great significance for practical applications. Consequently, the focus of this study is a new alloy design strategy, to prepare $\mathrm{FeAlCuCrNiMo}{ }_{0.6} \mathrm{Ti}_{x} \mathrm{HEAs}$ surfacing layer by gas metal arc welding (GMAW) technology, and to discuss the phase composition, microstructure of HEAs surfacing layer and the relationship between microstructure and comprehensive properties.

\section{Experimental}

\subsection{Preparation of the Surfacing Layer}

Metal powders of $\mathrm{Al}, \mathrm{Cu}, \mathrm{Cr}, \mathrm{Ni}, \mathrm{Mo}$ and $\mathrm{Ti}$ with purity level greater than $99.9 \mathrm{wt} \%$ were selected as raw materials and were added into the steel strip according to different ratios to roll and draw for a flux-cored wire of $2.4 \mathrm{~mm}$ in diameter. The powder filling rate is $35 \%$. Alloys with nominal composition of FeAlCuCrNiMo ${ }_{0.6} \mathrm{Ti}_{x}$ were prepared ( $x$ refers to molar ratio, and $x=0.2,0.6$ and 0.8 , and denoted as $\mathrm{Ti}_{0.2}, \mathrm{Ti}_{0.6}$ and $\mathrm{Ti}_{0.8}$, respectively). The compositions of the steel strip and the substrate are given in Table 1 . The powders need to be dried before preparation of flux-cored wire, because they are easy to absorb water and cause defects, such as pores and cracks in the weld [18].

Subsequently, the surface of substrate low-carbon steel was polished to remove oxides and then cleaned with pure ethanol. The powers were surfaced on the low-carbon steel by GMAW (argon: 99.99\%) to obtain $\mathrm{FeAlCuCrNiMo}{ }_{0.6} \mathrm{Ti}_{x}$ HEAs. The welding process parameters [19] are given in Table 2. The surfacing layers were cut into a square sample with a size of $10 \mathrm{~mm} \times 10 \mathrm{~mm} \times 10 \mathrm{~mm}$, grinded and polished and then etched by $4 \%$ nitric acid to observe microstructure.
Table 2 Welding process parameters

\begin{tabular}{llll}
\hline $\begin{array}{l}\text { Welding current } \\
\text { (A) }\end{array}$ & Arc voltage (V) & $\begin{array}{l}\text { Welding speed } \\
(\mathrm{cm} / \mathrm{min})\end{array}$ & $\begin{array}{l}\text { Gas flow (L/ } \\
\mathrm{min})\end{array}$ \\
\hline 160 & 24 & 8 & 12 \\
\hline
\end{tabular}

\subsection{Surfacing Layer Characterization}

Phase structure of surfacing layer was analyzed by X-ray diffraction (XRD), and working parameters were: current of $30 \mathrm{~mA}$, voltage of $40 \mathrm{kV}, \mathrm{Cu}$ target, scanning range from $20^{\circ}$ to $90^{\circ}$ and scanning speed of $4 \% \mathrm{~min}$. The grain structure and phase composition were characterized by a GeminiSEM 300 field emission scanning electron microscope equipped with an electron back-scatter diffraction (EBSD) and an energydispersive spectroscopy (EDS). Vickers hardness was determined under a load of $500 \mathrm{~g}$ for $15 \mathrm{~s}$ with microhardness tester (THVS-5). Wet sand rubber wheel wear tester was used to test the wear resistance of surfacing layers, and the parameters were: quartz sand of $250 \mu \mathrm{m}$, speed $240 \mathrm{r} / \mathrm{min}$ and a duration of $5 \mathrm{~min}$. BL410F electronic balance (1 mg) was used to compare the mass of surfacing layer samples before and after wearing test and then calculate the wear mass loss. Electrochemical polarization curves and electrochemical impedance spectroscopy of the HEAs surfacing layer in $3.5 \% \mathrm{NaCl}$ solution were measured by a electrochemical workstation (VSP-300), using the saturated calomel electrode as reference electrode and platinum electrode as the counter electrode at scanning speed of $10 \mathrm{mV} / \mathrm{min}$.

\section{Results and Discussion}

\subsection{Phase Structure}

According to thermodynamics, Zhang et al. [20] applied Hume-Rothery law to the composition design of multi-component HEAs. Based on the parameters of mixing entropy $\left(\Delta S_{\text {mix }}\right)$, mixing enthalpy $\left(\Delta H_{\text {mix }}\right)$ and atomic radius difference $(\delta)$ of multi-component alloys, the rules of solid-solution phase formation of HEAs are proposed as:

$\Delta S_{\text {mix }}=-R \sum_{i=1}^{n} C_{i} \ln C_{i}$,
Table 1 Compositions of H08A steel strip and substrate (wt\%)

\begin{tabular}{lllllll}
\hline & $\mathrm{C}$ & $\mathrm{Si}$ & $\mathrm{Mn}$ & $\mathrm{S}$ & $\mathrm{P}$ & $\mathrm{Fe}$ \\
\hline H08A & 0.03 & 0.01 & $0.30-0.55$ & 0.013 & 0.011 & $\mathrm{Bal}$ \\
Substrate & 0.20 & 0.35 & 0.70 & 0.045 & 0.045 & $\mathrm{Bal}$ \\
\hline
\end{tabular}




$$
\begin{aligned}
& \Delta H_{\text {mix }}=\sum_{i=1, i \neq j}^{n} 4 \Delta H_{i j}^{\text {mix }} C_{i} C_{j}, \\
& \delta=100 \sqrt{\sum_{i=1}^{n} C_{i}\left(1-\frac{r_{i}}{\bar{r}}\right)^{2}} \bar{r}=\sum_{i=1}^{n} r_{i} C_{i},
\end{aligned}
$$

where $r_{i}$ is the atomic radius of the $i$ th element, $C_{i}, C_{j}$ is the molar ratio, and $\Delta H_{i j}$ mix is the enthalpy of mixing between the $i$ th and $j$ th elements. The parameter $\Delta H_{\text {mix }}$ indicates the chemical compatibility among components, reflecting the tendency of formation for intermetallic compounds. According to the available data from different HEAs systems, the criteria for forming a random solid solution in HEAs were determined as $1 \%<\delta<6.6 \%,-15 \mathrm{~kJ} \cdot \mathrm{mol}^{-1}<\Delta H_{\text {mix }}<5$ $\mathrm{kJ} \cdot \mathrm{mol}^{-1}$ and $12 \mathrm{~J} \cdot \mathrm{mol}^{-1} \mathrm{~K}^{-1}<\Delta S_{\text {mix }}<17.5 \mathrm{~J} \cdot \mathrm{mol}^{-1} \mathrm{~K}^{-1}$. In the case that the alloy system can form a solid solution, the valence electron concentration (VEC) is an important parameter that affects whether the alloy forms a FCC phase or a BCC phase. Guo et al. [21] proposed a VEC to predict the phase stability of HEAs with the following formula:

$\mathrm{VEC}=\sum_{i=1}^{n} C_{i}(\mathrm{VEC})_{i}$

where $C_{i}$ is the atomic percentage and $(\mathrm{VEC})_{i}$ is the VEC for the $i$ th element, respectively. According to the formula, the parameter calculation result is given in Table 3. In Guo's study, when VEC $>8.0$, it is beneficial to the formation of FCC phase; when VEC $<6.87$, it is beneficial to the formation of BCC phase. When $6.87<\mathrm{VEC}<8.0$, two phases of $\mathrm{BCC}$ and $\mathrm{FCC}$ tend to coexist. Figure 1 shows the parameter values of $\mathrm{FeAlCuCrNiMo}{ }_{0.6} \mathrm{Ti}_{x} \mathrm{HEAs}$. It can be seen that our design system can be defined as a HEA, and it is reasonable that two phases of BCC and FCC coexist. When the $\mathrm{Ti}_{1.0}$ is calculated, the system also coexists in two phases, so this work only studies the first three alloys.

Figure 2 shows the X-ray diffraction patterns of FeAlCuCrNiMo ${ }_{0.6} \mathrm{Ti}_{x}(x=0.2,0.6,0.8)$ HEAs. The HEA surfacing layer is composed of a BCC phase and a small amount of MC phase, and the main phase of alloy is the BCC phase. It can be seen from the data of PDF cards that the

Table 3 Theoretical parameter values

\begin{tabular}{lllll}
\hline Element & $\begin{array}{l}\Delta S_{\text {mix }} \\
\left(\mathrm{J} \cdot \mathrm{mol}^{-1} \mathrm{~K}^{-1}\right)\end{array}$ & $\Delta(\%)$ & $\Delta H_{\text {mix }}\left(\mathrm{kJ} \cdot \mathrm{mol}^{-1}\right)$ & VEC \\
\hline $\mathrm{Ti}_{0.2}$ & 15.516 & 5.74 & -5.65 & 7.31 \\
$\mathrm{Ti}_{0.6}$ & 15.991 & 6.16 & -9.12 & 7.10 \\
$\mathrm{Ti}_{0.8}$ & 16.063 & 6.32 & -10.52 & 7.00 \\
$\mathrm{Ti}_{1.0}$ & 16.075 & 6.44 & -11.73 & 6.91 \\
\hline
\end{tabular}

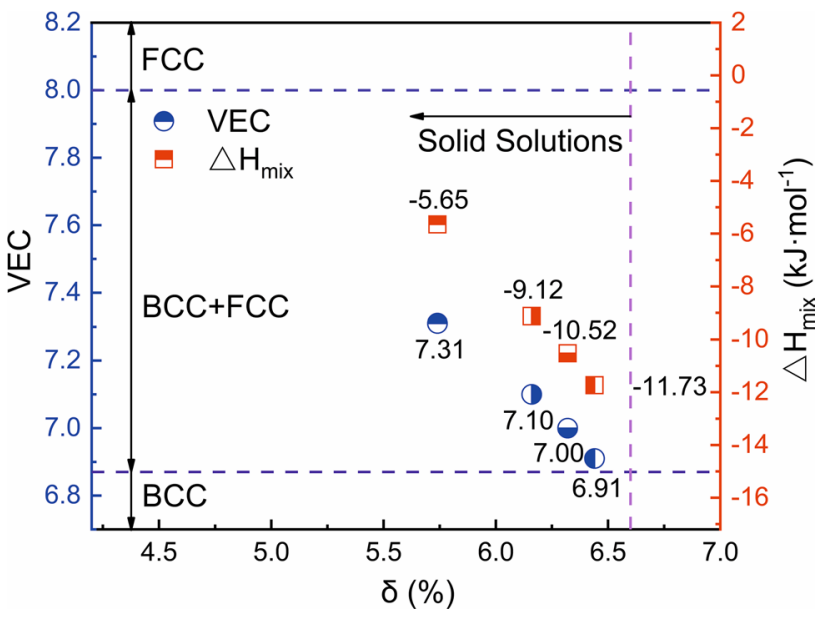

Fig. 1 Parameter values of $\mathrm{FeAlCuCrNiMo}{ }_{0.6} \mathrm{Ti}_{x} \mathrm{HEAs}$

phase peak of this phase is consistent with $\mathrm{Fe}-\mathrm{Cr}$, indicating that the FeAlCuCrNiMo ${ }_{0.6} \mathrm{Ti}_{x}$ HEA forms a solid solution based on $\mathrm{Fe}-\mathrm{Cr}$ phase during surfacing process. The small peaks appearing near the diffraction peaks $2 \theta=35.906^{\circ}$ and $2 \theta=41.710^{\circ}$ are ascribed to the FCC phase, shown in Fig. 2b, which is a magnified view of the dotted line in Fig. 2a; small amount of FCC phase is obtained as MC eutectic. The peak of MC phase is mainly due to TiC phase (PDF: 32-1383) [22]. With increasing Ti content, the MC phase always exists, and the diffraction peak does not shift. It is consistent with the previously calculated parameters for prediction, such as $\Delta S_{\mathrm{mix}}, \Delta H_{\mathrm{mix}}, \delta$ and VEC.

\subsection{Microstructures}

Figure 3 shows the microstructures and morphologies of FeAlCuCrNiMo ${ }_{0.6} \mathrm{Ti}_{x}(x=0.2,0.6,0.8)$ HEAs. It is known that the surfacing layer is mainly composed of dendritic structure. Typical gray dendritic (DR) and white interdendritic (ID) structures were clearly observed in $\mathrm{Ti}_{0.2}$, $\mathrm{Ti}_{0.6}$ and $\mathrm{Ti}_{0.8}$ HEAs (Fig. 3a-c). Furthermore, the closeup view showed that some fine particles precipitated in FeAlCuCrNiMo ${ }_{0.6} \mathrm{Ti}_{x}$ HEAs. The chemical compositions of different regions obtained by EDS are listed in Table 4. In $\mathrm{FeAlCuCrNiMo}{ }_{0.6} \mathrm{Ti}_{x} \mathrm{HEA}$ surfacing layer, DR was rich in $\mathrm{Fe}, \mathrm{Cr}$, $\mathrm{Ni}$ and depleted in $\mathrm{Cu}$, while ID was rich in $\mathrm{Cu}$, Mo, $\mathrm{Ti}$ and $\mathrm{Al}$ is partially burned. The precipitate is $\mathrm{TiC}$ phase. The amount of precipitated phase TiC gradually increases with the increase in $\mathrm{Ti}$ content. The reason is that $\mathrm{Ti}$ is a strong carbon compound forming element and a high volume fraction. However, the Fe content is higher, because the high-energy arc makes the heat absorption of surfacing layer increase, the $t_{8 / 5}$ of surfacing layer and substrate will become long, more Fe in the substrate diffuses to the surfacing layer, so the dilution is higher [23, 

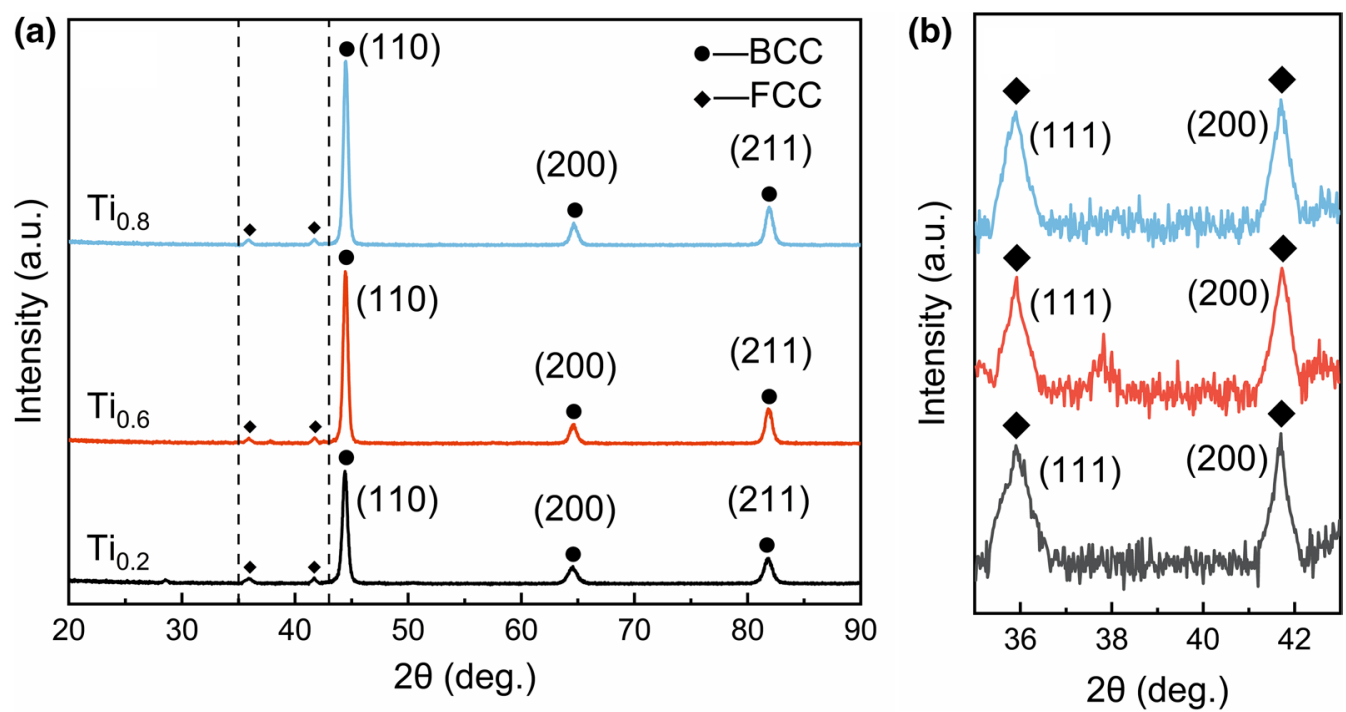

Fig. 2 X-ray diffraction patterns of $\mathrm{FeAlCuCrNiMo}{ }_{0.6} \mathrm{Ti}_{x}$ HEAs: a overall diagram, b FCC phase diagram
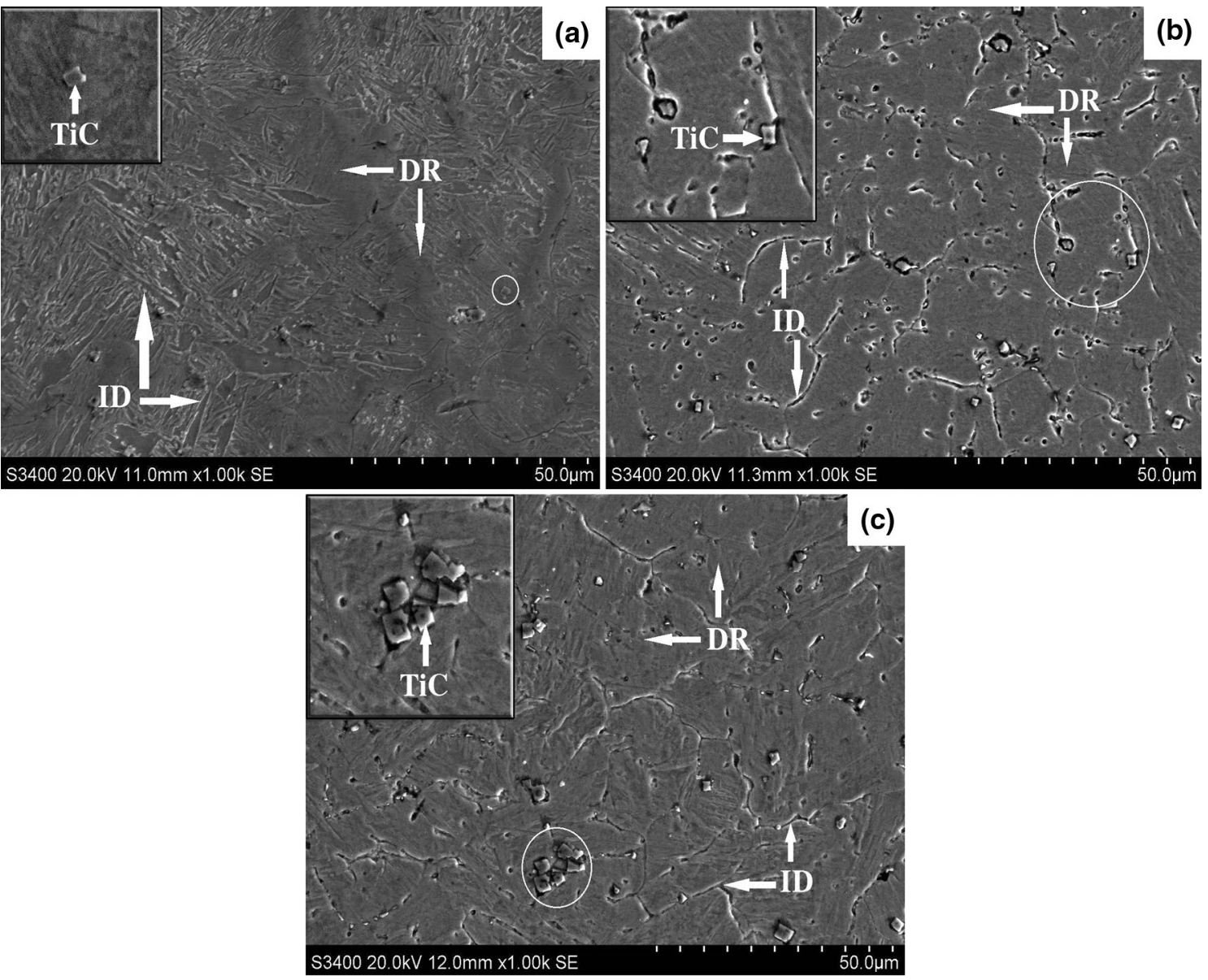

Fig. 3 Microstructures and morphologies of the FeAlCuCrNiMo ${ }_{0.6} \mathrm{Ti}_{x} \mathrm{HEAs} \mathbf{a} \mathrm{Ti}_{0.2}, \mathbf{b} \mathrm{Ti}_{0.6}, \mathbf{c} \mathrm{Ti}_{0.8}$ 
Table 4 Chemical compositions of $\mathrm{FeAlCuCrNiMo}{ }_{0.6} \mathrm{Ti}_{x}$ HEAs surfacing layer at various regions in Fig. 3 (at.\%)

\begin{tabular}{llllllllll}
\hline Alloys & Region & $\mathrm{Fe}$ & $\mathrm{Al}$ & $\mathrm{Cu}$ & $\mathrm{Cr}$ & $\mathrm{Ni}$ & $\mathrm{Mo}$ & $\mathrm{Ti}$ & $\mathrm{C}$ \\
\hline $\mathrm{Ti}_{0.2}$ & Precipitates & $25.99 \mathrm{~s}$ & 7.35 & 2.70 & 1.56 & 2.35 & 0.69 & 48.29 & 11.07 \\
& $\mathrm{DR}$ & 70.11 & 2.39 & 5.83 & 9.35 & 9.60 & 1.12 & 1.60 & - \\
& $\mathrm{ID}$ & 63.92 & 3.30 & 10.63 & 7.24 & 7.47 & 4.08 & 55.73 & - \\
$\mathrm{Ti} 0.6$ & Precipitates & 14.17 & 7.82 & 2.57 & 1.72 & 2.21 & 0.79 & 3.36 & 14.99 \\
& DR & 69.57 & 2.24 & 4.21 & 10.32 & 9.56 & 1.56 & 2.54 & - \\
& ID & 57.30 & 3.37 & 13.02 & 8.12 & 7.69 & 4.14 & 6.36 & - \\
Ti0.8 & Precipitates & 10.92 & 8.53 & 1.65 & 1.74 & 1.34 & 0.47 & 62.47 & 12.86 \\
& DR & 67.11 & 2.88 & 6.42 & 10.33 & 9.13 & 1.43 & 2.70 & - \\
& ID & 62.01 & 3.16 & 9.15 & 8.06 & 7.49 & 3.98 & 6.15 & - \\
\hline
\end{tabular}

24]. Combined with XRD analysis, the microstructure is mainly $\mathrm{Fe}-\mathrm{Cr}$ phase with BCC structure, and the fine particles of TiC are usually dispersed in alloy matrix [22].

Figure 4 shows the EDS maps of FeAlCuCrNiMo ${ }_{0.6} \mathrm{Ti}_{0.8}$ HEA. It can be seen that $\mathrm{Ti}$ element rich in white bulk particles substantially coincides with C. From this, it was confirmed that the white particles were TiC phase. The distribution of TiC can only be judged by the content of $\mathrm{Ti}$, because there is always a large error in the content of C obtained by EDS [23].

Figure 5 shows the EBSD texture maps and the grain size of FeAlCuCrNiMo ${ }_{0.6} \mathrm{Ti}_{x}(x=0.2,0.6,0.8)$ HEAs. These images exhibit the colors corresponding various grain orientations, as indicated by the unit triangles in Fig. 5a. It shows that the microstructure consists of many blocky, elongated and small amounts of equiaxed grains [23]. After calculating the average grain size, the value is $3.27 \mu \mathrm{m}$ for $\mathrm{Ti}_{0.2}, 3.26 \mu \mathrm{m}$ for $\mathrm{Ti}_{0.6}$ and $3.19 \mu \mathrm{m}$ for $\mathrm{Ti}_{0.8}$. With increasing amount of $\mathrm{Ti}$, the grain size decreased, the texture orientation distribution was uneven, and the grain did not have preferred growth orientation. For $\mathrm{Ti}_{0.8}$, the ratio of grains size (the area fraction) of less than $3.0 \mu \mathrm{m}$ increased from $74.5 \%$ to $78 \%$, as shown in Fig. $5 \mathrm{~b}$, $\mathrm{d}$ and $\mathrm{f}$. In summary, the addition of $\mathrm{Ti}$ is advantageous for grains refinement.

Figure 6 shows the EBSD phase maps and histograms of the phase of FeAlCuCrNiMo ${ }_{0.6} \mathrm{Ti}_{x}(x=0.2,0.6,0.8)$ HEAs. There is a majority of BCC, few FCC phase and an unknown phase, the red region represents the $\mathrm{BCC}$ phase, and the blue and yellow-green regions represent FCC phases. As can be seen in Fig. 6a, c and e, FCC phases are mainly dispersed in BCC grains, and the proportion increases gradually. EBSD results are consistent with the $\mathrm{XRD}$ results, and the surfacing layers are mainly composed of solid solutions including FCC and BCC phases. The BCC phase occupies most of the area. In Fig. 6b, $\mathrm{d}$ and $\mathrm{f}$, due to the addition of $\mathrm{Ti}$, the FCC phase ratio increases, the $\mathrm{FCC}$ phase in $\mathrm{Ti}_{0.8}$ is $0.96 \%$, and the ratio of BCC to FCC phase is 101.9.

\subsection{Microhardness and Wear Resistance}

Figure 7 shows the microhardness profiles along the cross section of the FeAlCuCrNiMo ${ }_{0.6} \mathrm{Ti}_{x}(x=0.2,0.6,0.8)$ HEAs. With increasing Ti content, the normal direction microhardness of HEAs surfacing layer increases gradually. The highest microhardness of HEAs surfacing layer can reach 642 $\mathrm{HV}_{0.5}$, which was at least 2.8 times that of substrate, and the thickness of surfacing layer is about $3.0 \mathrm{~mm}$. In addition, the microhardness of fusion zone is lower than that of upper surface. Figure 8 shows the cross-sectional microstructure of FeAlCuCrNiMo ${ }_{0.6} \mathrm{Ti}_{0.8}$ HEA. The surfacing layer is mainly composed of solid solutions including FCC and BCC phases, where it contains many elements. These alloy elements enhance the microhardness of the surfacing layer by solid-solution strengthening and precipitation strengthening. The fusion zone is located in the transition zone between the surfacing layer and the substrate metal. The fusion zone experienced obvious element diffusion and migration due to the action of welding heat. The composition of fusion zone should be a mixture of substrate and surfacing layer, and the microhardness of fusion zone is also between them. Therefore, the microhardness of the surfacing layer is the highest, and that of the fusion zone is lower.

Figure 9 shows the comparison of average microhardness and wear mass loss of FeAlCuCrNiMo${ }_{0.6} \mathrm{Ti}_{x}(x=0.2,0.6$, $0.8)$ HEAs. Intuitively, the microhardness curve of surfacing layer is increasing, and the average microhardness of $\mathrm{Ti}_{0.8}$ is the highest $\left(626 \mathrm{HV}_{0.5}\right)$; The wear mass loss curve showed a decreasing trend, and the amount of wear mass loss of $\mathrm{Ti}_{0.8}$ was the smallest $(0.28 \mathrm{~g})$. It is suggested that the smaller the crystal grains of material, the higher the microhardness, and the better the wear resistance of alloy. The average microhardness of substrate is $229 \mathrm{HV}_{0.5}$, which is lower than the microhardness of HEAs surfacing layer. Ti is a strong carbide forming element, the atomic radius is relatively large, lattice distortion occurs, and the resistance of dislocation motion is enhanced, so that the microhardness of alloy is much higher than that of substrate $[25,26]$. 

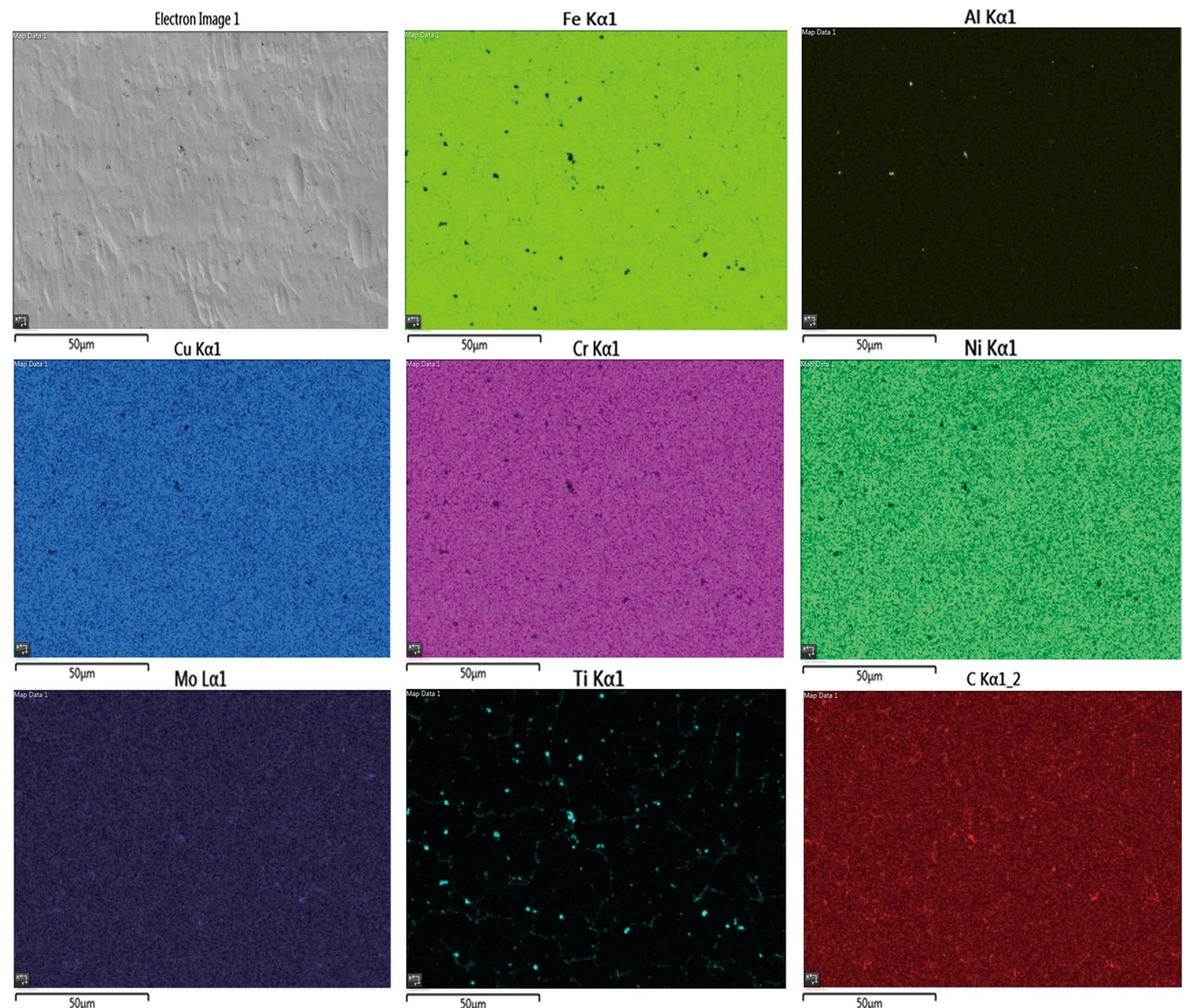

Fig. 4 Qualitative element distribution EDS maps of FeAlCuCrNiMo ${ }_{0.6} \mathrm{Ti}_{0.8} \mathrm{HEAs}$

The Fe-Cr solid solution of BCC structures in alloy inflicts solid-solution strengthening, and the fine particle TiC precipitation strengthening effect of FCC phase improves the microhardness of alloy [27-29]. Comparing the atomic radius of each element with $\mathrm{Fe}-\mathrm{Cr}$ lattice gap, the following relationship exists:

$R(\mathrm{Ti})>R(\mathrm{Al})>R(\mathrm{Cu})>R(\mathrm{Ni})>R(\mathrm{Cr})>R(\mathrm{Fe})>$ Lattice gap

Since the $\mathrm{Fe}$ and $\mathrm{Cr}$ atomic radius difference and the electronegativity are smaller than those of other atoms, it is impossible for metal atom to exist in the unit cell as an interstitial solid solution, and it is most likely that it exists in the surfacing layer in a form of substitutional solid solution. Compared with other elements, the atomic radius of Ti element is relatively large. The addition of
Ti element may produce a substitutional solid solution. As the Ti content increases, the entropy value increases, the Gibbs free energy decreases, the degree of alloy chaos increases, and element segregation is reduced, the phase is more stable [30]. According to the above analysis, there are two strengthening mechanisms in the test alloy system, namely solid-solution strengthening and precipitation strengthening, and the two strengthening effects enhance the mechanical properties of alloy as well.

\subsection{Corrosion Resistance}

Figure 10 shows the electrochemical polarization curves in $3.5 \mathrm{wt} \% \mathrm{NaCl}$ solution for 304 stainless steel and FeAlCuCrNiMo ${ }_{0.6} \mathrm{Ti}_{x}(x=0.2,0.6,0.8)$ HEAs. The selfcorrosion potential and self-corrosion current density of 

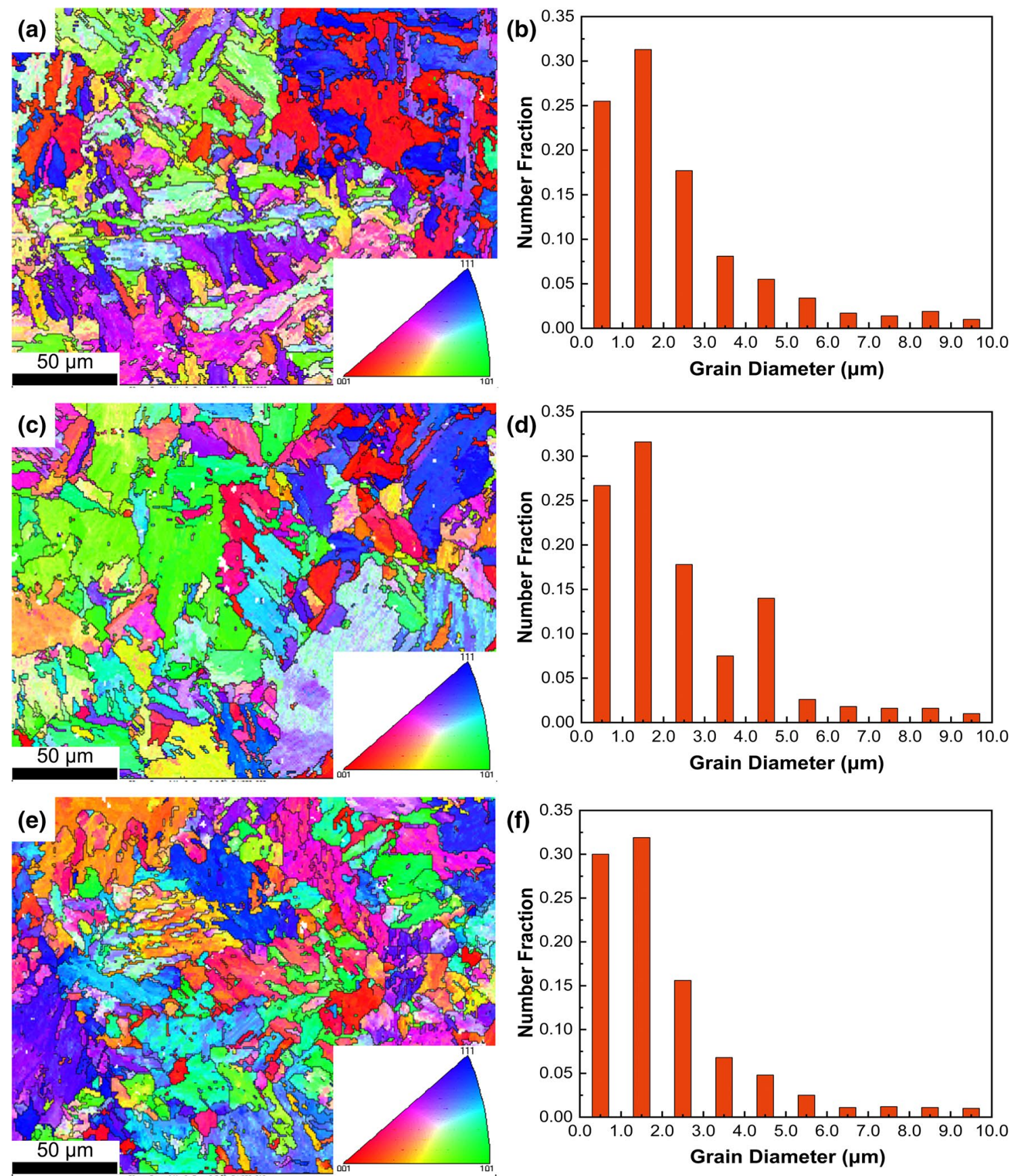

Fig. 5 EBSD texture maps and grain sizes of FeAlCuCrNiMo ${ }_{0.6} \mathrm{Ti}_{x} \mathrm{HEAs:} \mathbf{a}, \mathbf{b} \mathrm{Ti}_{0.2}, \mathbf{c}, \mathbf{d ~ T i} \mathrm{T}_{0.6}, \mathbf{e}, \mathbf{f} \mathrm{Ti}_{0.8}$

$\mathrm{FeAlCuCrNiMo}_{0.6} \mathrm{Ti}_{x}$ HEAs surfacing layer with different $\mathrm{Ti}$ contents are not consistent with each other. With increasing Ti content, the self-corrosion potential firstly increases and then decreases, and the self-corrosion current density decreases at first and then increases. The selfcorrosion potential is an important parameter of measuring the thermodynamics of corrosion reaction. The higher the potential, the more difficult the corrosion reaction begins. Self-corrosion current density is a physical parameter that reflects the kinetics of reaction. The smaller the current density, the slower the corrosion rate $[31,32]$. Since the corrosion rate is positively correlated with the self-corrosion current, the corrosion rate of HEAs also decreases at first and then increases. The data of self-corrosion potential and self-corrosion current density are given in Table 5. It can be concluded that $\mathrm{FeAlCuCrNiMo}{ }_{0.6} \mathrm{Ti}_{0.6}$ has best corrosion resistance, which possesses the highest self-corrosion potential, about $-1.03409 \mathrm{~V}$, and the lowest self-corrosion current 

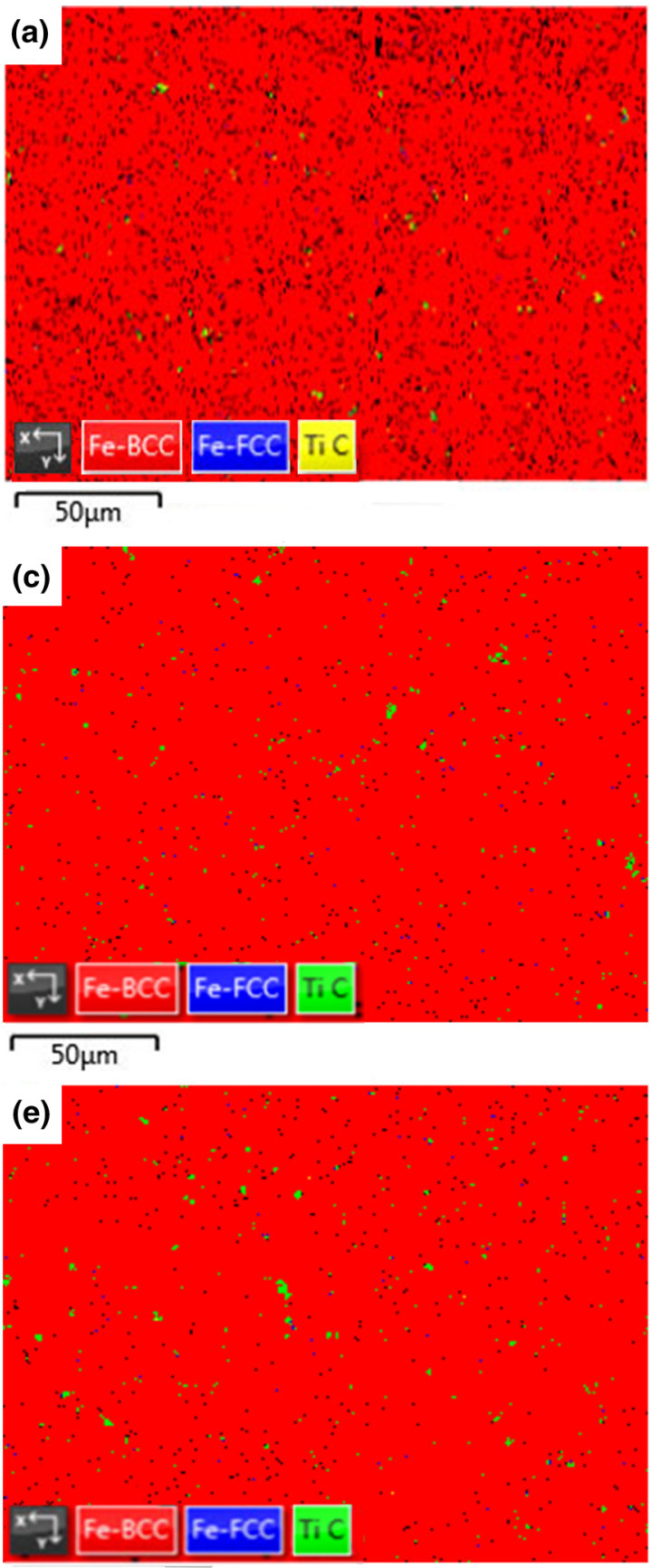

$50 \mu \mathrm{m}$
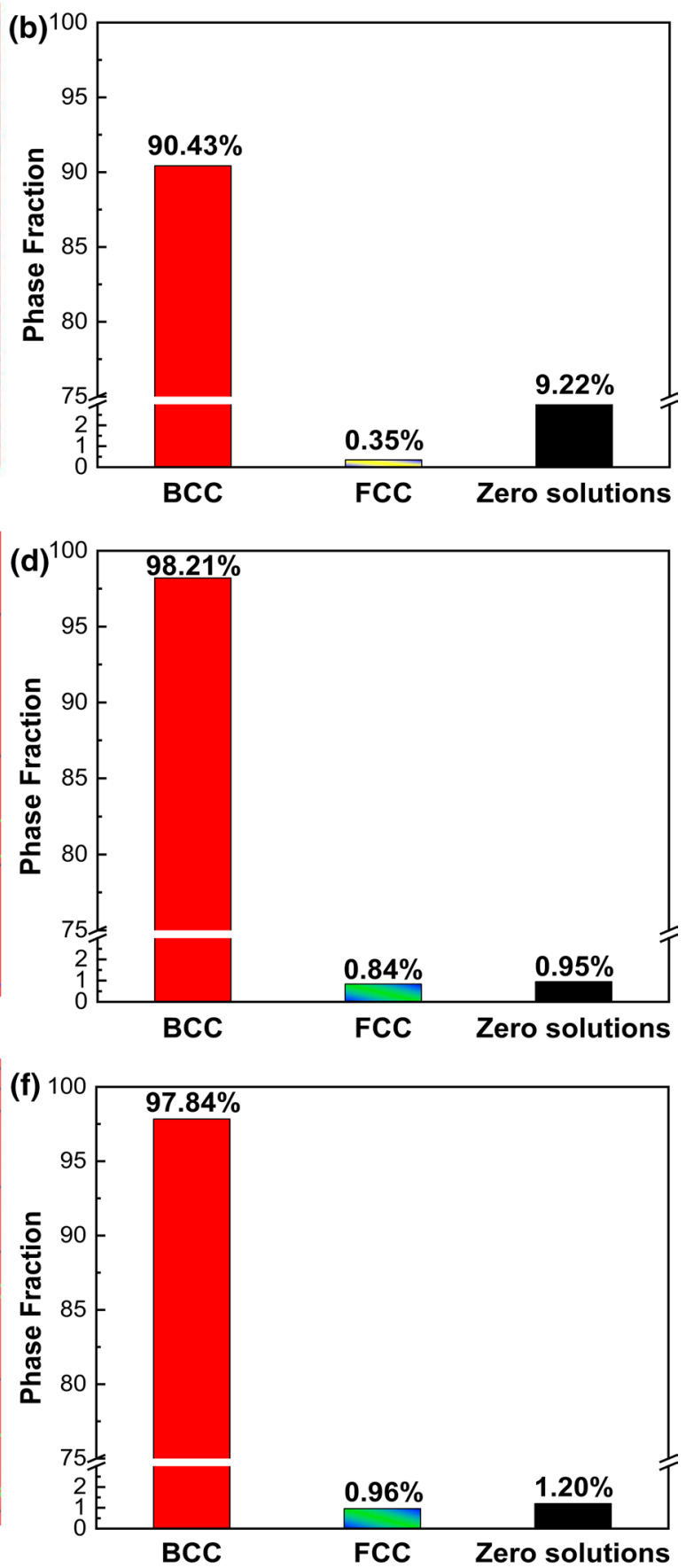

Fig. 6 EBSD phase maps and histograms of phases within $\mathrm{FeAlCuCrNiMo}{ }_{0.6} \mathrm{Ti}_{x} \mathrm{HEAs:} \mathbf{a}, \mathbf{b} \mathrm{Ti}_{0.2}, \mathbf{c}, \mathbf{d ~ T i}{ }_{0.6}, \mathbf{e}, \mathbf{f} \mathrm{Ti}_{0.8}$

density, about $2.1276 \times 10^{-4} \mathrm{~mA} / \mathrm{cm}^{2}$. Compared with 304 stainless steel, HEAs surfacing layer has better corrosion resistance, smaller self-corrosion current density and higher corrosion potential.

Figure 11 shows Nyquist plots of 304 stainless steel and $\mathrm{FeAlCuCrNiMo}_{0.6} \mathrm{Ti}_{x}(x=0.2,0.6,0.8)$ HEAs in $3.5 \mathrm{wt} \%$ $\mathrm{NaCl}$ solution. The impedance spectra are expressed in the high-frequency region, when the capacitive reactance arcs form parallel connections at the charge transfer resistance. During the corrosion process, the passivation film is continuously damaged by the $\mathrm{Cl}^{-}$-induced corrosion in solution, the impedance gradually reduces, and the arc gradually shrinks. In addition, in this process, an inductive arc appears in the low-frequency region, which is related to the passivation film and $\mathrm{Cl}^{-}$-induced corrosion $[33,34]$. The smoother the amplitude-frequency curve, 


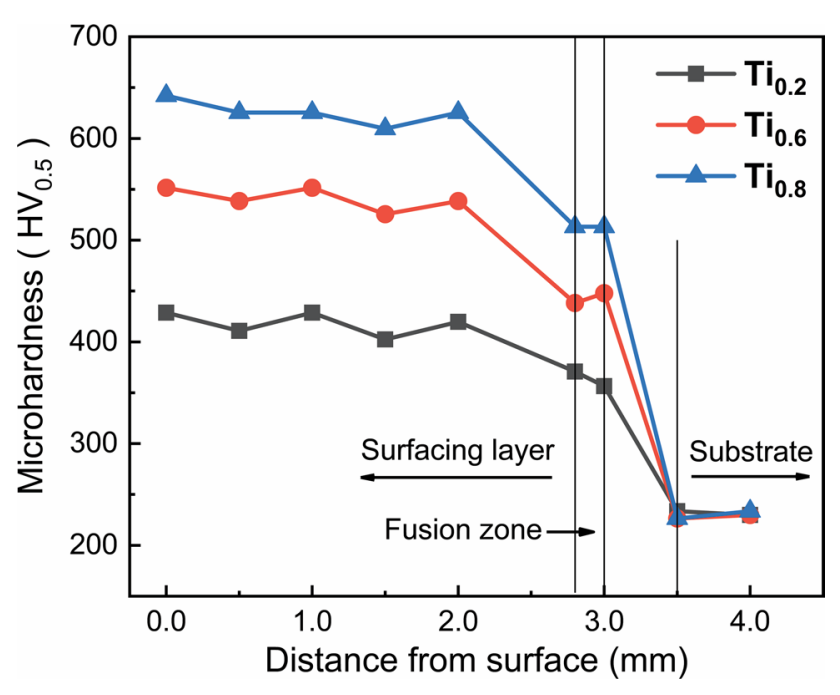

Fig. 7 Microhardness distributions of $\mathrm{FeAlCuCrNiMo}{ }_{0.6} \mathrm{Ti}_{x} \mathrm{HEAs}$

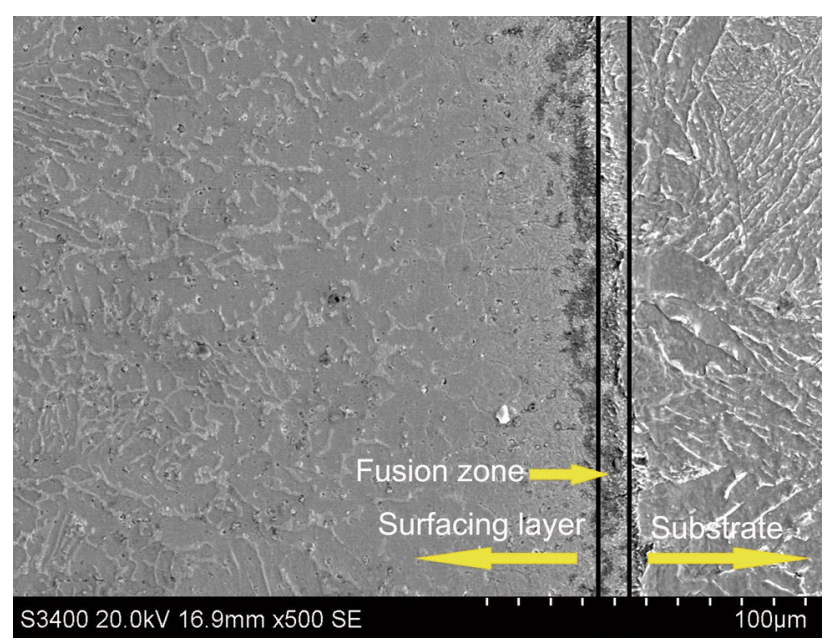

Fig. 8 Cross-sectional microstructure of $\mathrm{FeAlCuCrNiMo}{ }_{0.6} \mathrm{Ti}_{0.8} \mathrm{HEA}$

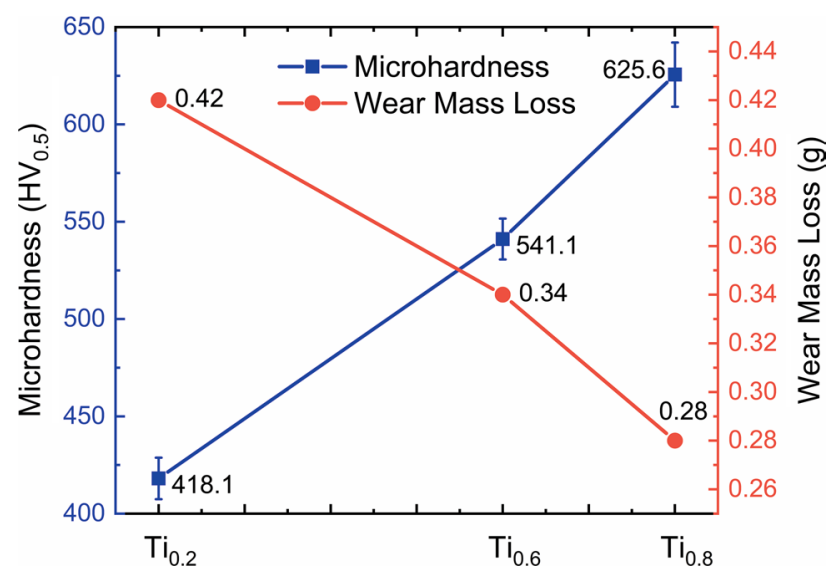

Fig. 9 Comparison of microhardness and wear mass loss of $\mathrm{FeAlCuCrNiMo}_{0.6} \mathrm{Ti}_{x} \mathrm{HEAs}$

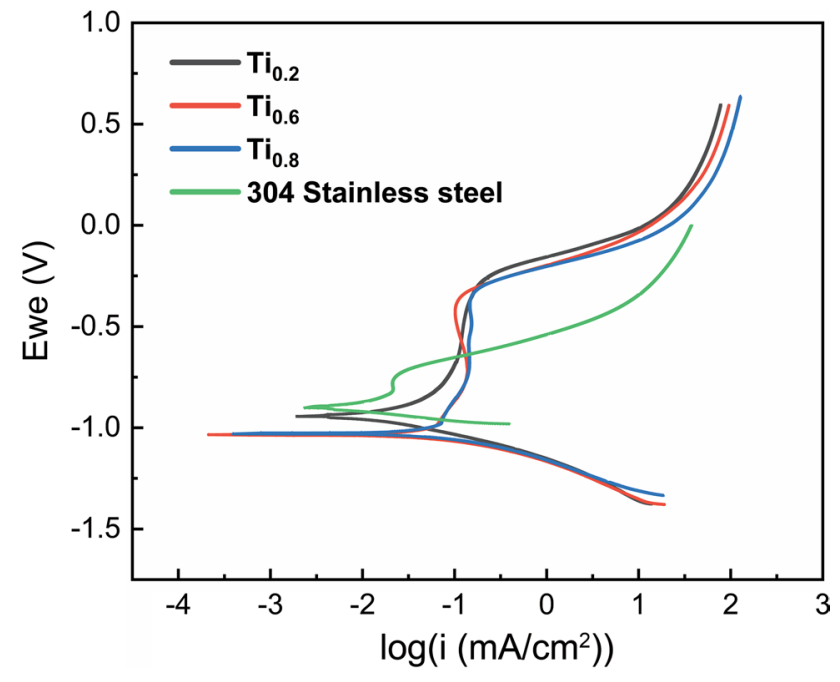

Fig. 10 Electrochemical polarization curves of FeAlCuCrNiMo ${ }_{0.6} \mathrm{Ti}_{x}$ HEAs

Table 5 Self-corrosion potential and current density of FeAlCuCrNiMo ${ }_{0.6} \mathrm{Ti}_{x}$ HEAs surfacing layer

\begin{tabular}{lll}
\hline HEA surfacing layer & $\begin{array}{l}\text { Self-corrosion } \\
\text { potential }(\mathrm{V})\end{array}$ & $\begin{array}{l}\text { Self-corrosion cur- } \\
\text { rent density }(\mathrm{mA} / \\
\mathrm{cm}^{2}\end{array}$ \\
\hline 304 Stainless steel & -0.9008 & $2.3549 \times 10^{-3}$ \\
$\mathrm{Ti}_{0.2}$ & -0.9437 & $1.9474 \times 10^{-3}$ \\
$\mathrm{Ti}_{0.6}$ & -1.03409 & $2.1276 \times 10^{-4}$ \\
$\mathrm{Ti}_{0.8}$ & -1.03038 & $3.9298 \times 10^{-4}$ \\
\hline
\end{tabular}

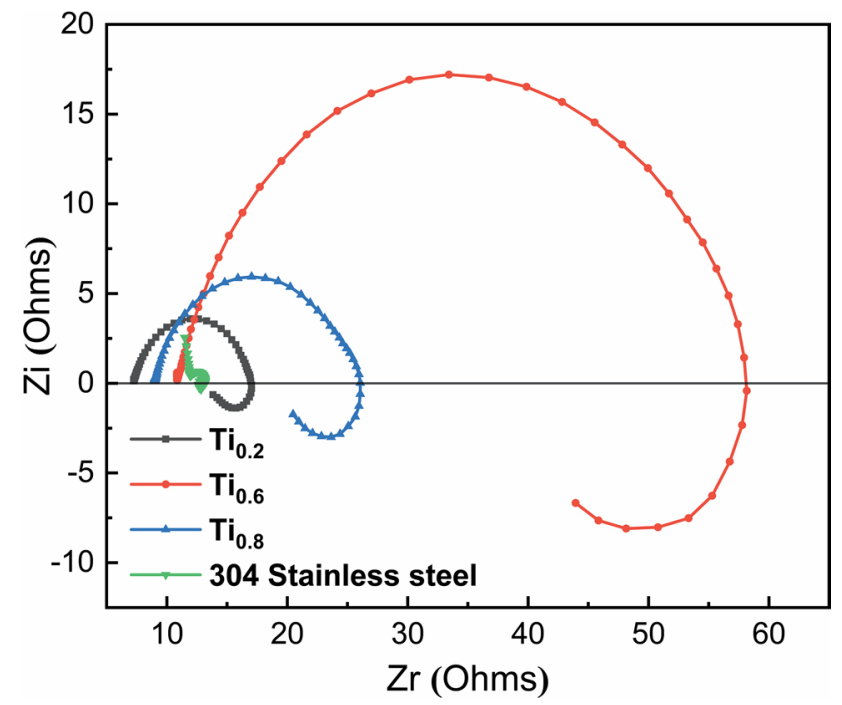

Fig. 11 Nyquist plots of $\mathrm{FeAlCuCrNiMo}{ }_{0.6} \mathrm{Ti}_{x}$ HEAs 

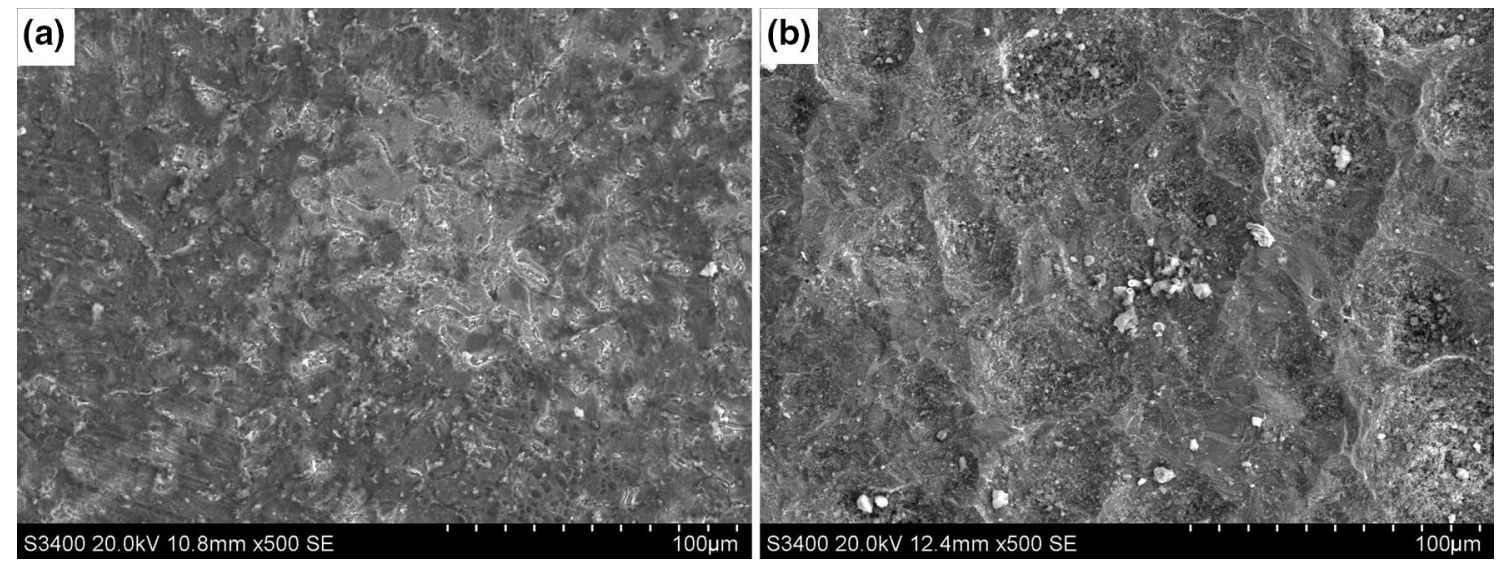

Fig. 12 Corrosion morphologies of $\mathrm{FeAlCuCrNiMo}{ }_{0.6} \mathrm{Ti}_{x} \mathrm{HEAs}$ : a FeAlCuCrNiMo${ }_{0.6} \mathrm{Ti}_{0.6}$, b 304 stainless steel

the smaller the corrosion variation, indicating that the corrosion resistance is worse; the larger the radius of the capacitive arc, the better the corrosion resistance [35]. It can be seen from Fig. 11 that the corrosion rate decreases at first and then increases, and the $\mathrm{Ti}_{0.6}$ has the largest radius of capacitance and the best corrosion resistance. This is because the $\mathrm{BCC}$ structure is dominant in $\mathrm{Ti}_{0.6}$, and the $\mathrm{BCC}$ structure is mainly related to $\mathrm{Fe}-\mathrm{Cr}$ phase, which contains a large amount of $\mathrm{Cr}$ element, and the passivation film can be more easily formed [36]. On the other hand, $\mathrm{Ti}_{0.6}$ has the lowest self-corrosion current density and the highest charge transfer resistance. Therefore, the capacitance radius of $\mathrm{Ti}_{0.6}$ is much larger than other components, and the corrosion resistance is the best.

Figure 12 shows the corrosion morphologies of $\mathrm{FeAlCuCrNiMo}_{0.6} \mathrm{Ti}_{x}(x=0.2,0.6,0.8)$ HEAs. The difference in morphologies is obvious by comparing Fig. 12a and $\mathrm{b}$; the corrosion resistance of $\mathrm{FeAlCuCrNiMo}{ }_{0.6} \mathrm{Ti}_{x}$ HEAs is stronger than that of 304 stainless steel, which is mainly due to the single solid-solution phase, and the improved corrosion resistance of alloy. The microstructure corrosion of $\mathrm{FeAlCuCrNiMo}{ }_{0.6} \mathrm{Ti}_{x}$ HEAs occurs mostly within the interdendritic region. From the comparison of EDS components of DR and ID in Table 4, it is known that the dendritic region is less $\mathrm{Cu}$ and the interdendritic region is rich in $\mathrm{Cu}$ forming a galvanic couple, resulting in the intergranular zone to be firstly corroded [37]. The less phase of corroded material during electrochemical corrosion process guarantees more uniform structure and provides more favorable corrosion resistance of alloy [38]. $\mathrm{Cr}$ and $\mathrm{Ni}$ elements are easily passivated in oxidative medium, which is beneficial to the formation of passivation film on the surface of alloy, thereby preventing the corrosion from proceeding further. On the other hand, the single solid-solution phase improves the corrosion resistance of alloy [39].

\section{Conclusions}

1. $\mathrm{FeAlCuCrNiMo}{ }_{0.6} \mathrm{Ti}_{x}$ HEAs surfacing layer was prepared on the surface of low-carbon steel by gas metal arc welding technology. The microstructure of alloy system is dominated by a body-centered cubic $\mathrm{Fe}-\mathrm{Cr}$ solidsolution phase with a small amount of carbide (TiC).

2. The microstructure of surfacing alloy is a typically dendritic structure. With the addition of titanium, the grain size becomes smaller and the grain boundaries increase. The alloy system shows a combination of solid-solution strengthening and precipitation strengthening effects.

3. The addition of titanium can significantly improve the microhardness and wear resistance of surfacing layer. FeAlCuCrNiMo ${ }_{0.6} \mathrm{Ti}_{0.8}$ has a microhardness of up to 642 $\mathrm{HV}_{0.5}$ and a wear mass loss of $0.28 \mathrm{~g}$. The addition of titanium brings about more significant corrosion resistance than 304 stainless steel, and the appropriate amount of Ti content for corrosion resistance can be optimized, and $\mathrm{FeAlCuCrNiMo}{ }_{0.6} \mathrm{Ti}_{0.6}$ has the best electrochemical corrosion resistance.

Acknowledgements This work was financially supported by the National Key R\&D Program of China (No. 2017YFB1103603) and the Natural Science Foundation Program Key Projects of Liaoning Province (No. 20180510030).

\section{References}

[1] H. Guo, J. Eckert, Nat. Mater. 2, 33 (2003)

[2] K.H. Huang, J.W. Yeh, Dissertation (National Tsing Hua University, Hsinchu, 1996)

[3] J.W. Yeh, S.K. Chen, S.J. Lin, J.Y. Gan, T.S. Chin, T.T. Shun, C.H. Tsau, S.Y. Chang, Adv. Eng. Mater. 6, 299 (2004)

[4] J.W. Yeh, Ann. Chim. Sci. Mat. 6, 633 (2006) 
[5] Y. Zhang, T.T. Zuo, Z. Tang, M.C. Gao, K. Dahmen, P.K. Liaw, Z.P. Lu, Prog. Mater. Sci. 61, 1 (2014)

[6] J.M. Zhu, H.F. Zhang, H.M. Fu, A.M. Wang, H. Li, Z.Q. Hu, Mater. Sci. Eng. A 527, 6975 (2010)

[7] A.V. Kuznetsov, D.G. Shaysultanov, N.D. Stepanov, G.A. Salishchev, O.N. Senkov, Mater. Sci. Eng. A 533, 107 (2012)

[8] Y.Y. Chen, U.T. Hong, H.C. Shih, J.W. Yeh, T. Duval, Corros. Sci. 47, 2699 (2005)

[9] Y.J. Zhou, Y. Zhang, Y.L. Wang, G.L. Chen, Appl. Phys. Lett. 90, 181904 (2007)

[10] H.F. Sun, N. Guo, C.M. Wang, Z.Z. Li, H.Y. Zhu, Appl. Mech. Mater. 66, 894 (2011)

[11] F. Otto, A. Dlouhy, C. Somsen, Acta Mater. 61, 5743 (2013)

[12] C.C. Juan, M.H. Tsai, C.W. Tsai, C.M. Lin, W.R. Wang, C.C. Yang, S.K. Chen, S.J. Lin, J.W. Yeh, Intermetallics 62, 76 (2015)

[13] Y.D. Wu, Y.H. Cai, T. Wang, J.J. Si, J. Zhu, Y.D. Wang, X.D. Hui, Mater. Lett. 130, 277 (2014)

[14] C.L. Wu, S. Zhang, C.H. Zhang, H. Zhang, S.Y. Dong, J. Alloys Compd. 698, 761 (2017)

[15] T. Fujieda, H. Shiratori, K. Kuwabara, M. Hirota, T. Kato, K. Yamanaka, Y. Koizumi, A. Chiba, S. Watanabe, Mater. Lett. 189, 148 (2017)

[16] H. Zhang, Y. Pan, Y.Z. He, H.S. Jiao, Appl. Surf. Sci. 257, 2259 (2011)

[17] Y. Zou, S. Maiti, W. Steurer, R. Spolenak, Acta Mater. 65, 85 (2014)

[18] H. B. Wang, Dissertation, Beijing University of Technology, 2014

[19] S.L. Wang, L. Cui, H. Liu, X. Wang, Chin. Weld. 4, 46 (2018)

[20] Y. Zhang, Y.J. Zhou, J.P. Lin, G.L. Chen, P.K. Liaw, Adv. Eng. Mater. 10, 534 (2008)

[21] S. Guo, C. Ng, J. Lu, C.T. Liu, J. Appl. Phys. 109, 103505 (2011)

[22] X.J. Shang, Q.B. Liu, Y.X. Guo, J. Funct. Mater. 48, 12214 (2017)

[23] X.F. Li, Y.H. Feng, B. Liu, X.H. Yang, W.D. Zhang, G. Chen, Y. Liu, P.K. Bai, J. Alloys Compd. 788, 454 (2019)
[24] J.B. Cheng, D. Liu, X.B. Liang, Y.X. Chen, Surf. Coat. Technol. 281, 109 (2015)

[25] C. Qin, Z.K. Yao, W. Zhou, H.Z. Guo, J.X. Cao, Trans. China Weld. Inst. 33, 33 (2012)

[26] N.D. Stepanov, NYu Yurchenko, D.G. Shaysultanov, Mater. Sci. Technol. 31, 1139 (2015)

[27] C.J. Tong, Y.L. Chen, J.W. Yeh, S.J. Lin, S.K. Chen, T.T. Shun, C.H. Tsau, S.Y. Chang, Metall. Mater. Trans. A 36, 881 (2005)

[28] S.T. Chen, W.Y. Tang, Y.F. Kuo, S.Y. Chen, C.H. Tsau, T.T. Shun, J.W. Yeh, Mater. Sci. Eng. A 527, 5818 (2010)

[29] V. Braic, M. Balaceanu, M. Braic, A. Vladescu, S. Panseri, A. Russo, J. Mech. Behav. Biomed. 10, 197 (2012)

[30] H. Y. Zhao, Dissertation, Dalian University of Technology (2015)

[31] C.L. Wu, S. Zhang, C.H. Zhang, H. Zhang, S.Y. Dong, Surf. Coat. Technol. 315, 368 (2017)

[32] Y.X. Guo, X.J. Shang, Q.B. Liu, Surf. Coat. Technol. 344, 353 (2018)

[33] Y. Li, D.Y. Lin, Y.X. Chen, Y. Zheng, Corros. Sci. Prot. Technol. 28, 455 (2016)

[34] Z.H. Sun, N. Zhang, J.P. Cai, M. Liu, F. Lu, Acta Aeron. Astronaut. Sin. 29, 746 (2008)

[35] C.N. Cao, Introduction of Electrochemical Impedance Spectra (Science Press, Beijing, 2002), p. 70

[36] H. Zhang, Y. Zou, Z.D. Zou, D.T. Wu, Opt. Laser Technol. 65, $119(2015)$

[37] J.B. Cheng, X.B. Liang, B.S. Xu, Surf. Coat. Technol. 240, 184 (2014)

[38] Q. Jia, Dissertation, Harbin University of Science and Technology (2015)

[39] Y.Y. Chen, T. Duval, U.D. Hung, J.W. Yeh, H.C. Shih, Corros. Sci. 47, 2279 (2005) 